\title{
PARASITOLOGICAL DIAGNOSIS OF MUCOCUTANEOUS LEISHMANIASIS DUE TO LEISHMANIA B. BRAZILIENSIS IN BOLIVIA
}

\author{
Laure Dimier-David, Christophe David, Pierre Ravisse, Renato Bustillos, \\ Susana Revollo, Philippe Lyèvre, Maruschka Muñoz, \\ Fernando Vargas and Jean-Pierre Dedet
}

\section{SUMMARY}

\begin{abstract}
Parasitological diagnosis, using staned smears, culture and pathological examination of biopsy, was studied in 146 patients infected with mucocutaneous leishmaniasis, in Bolivia and Peru. The most efficient parasite detecting technique appeared to be the smear examination in cutaneous lesions (33\% positive) and the pathology in case of mucous lesions (28\% positive). In both, cutaneous and mucous lesions, the parasites were found most frequently in old lesions.
\end{abstract}

Key-words: Mucocutaneous leishmaniasis. Leishmania b. braziliensis. Diagnosis. Parasite. Bolivia. Peru.

Mucocutaneous leishmaniasis due to Leishmania braziliensis braziliensis Vianna 1911, is endemic in a large part of the American continent ${ }^{8}$. In Bolivia, it represents a public health problem because of its individual implications and socioeconomical consequences on development of various parts of the country ${ }^{2}$.

A positive diagnosis determines of parasites patient treatment. It is based on direct evidence in the lesions, which represents certainty of the disease.

The objective of this document is to present the results of $L . b$. braziliensis isolations using different techniques, in patients affected with primary cutaneous lesions or with mucosal secondary dissemination.

\footnotetext{
Instituto Boliviano de Biologia de Altura, c/o Embajada de Francia and Servicio de Otorrinolaringologia, Hospital das Clínicas, La Paz, Bolivia. Unité d'Histopathologie, Institut Pasteur, Paris, France.

Adress to correspondence: Dr. Jean-Pierre Dedet, Laboratoire d'Ecologie Médicale et Parasitologie Parasitaire, Annexe de la Faculté de Médecine, 163 rue Auguste Broussonet, 34000 Montpellier France.

Recebido para publicação em 01/07/91.
}

\section{MATERIAL AND METHODS}

The study was realized within a sample of 146 patients which were seen at the parasitology department of the Instituto Boliviano de Biologia de Altura (La Paz; Bolivia) between 1988 and 1990. They originated from the endemic areas neighbouring La Paz (Yungas, Alto Beni and Beni in Bolivia, Puno and Madre de Dios departments in Peru).

For each patient, the search for parasite was simultaneously conducted using the three following techniques:

1. smears made with material obtained from scratching the cutaneous lesion periphery or by imprints of biopsy section in case of mucous lesion. The smears were fixed by methanol and Giemsa stained;

2. culture inoculation on biphasic NNN medium containing Schneider medium and antibiotics as the liquid phase, of material obtained from scratching or biopsying the lesion. The isolates obtained were then characterized by isoenzyme electrophoresis ${ }^{6}$;

3. pathological examination of biopsy material. The biopsy material was taken with a $4 \mathrm{~mm}$ punch biopsy on the edge of the cutaneous lesion or with a cutting biopsy forceps in the case of mucous lesion, and 
Dimier-David L, David C, Ravisse $P$, Bustillos $R$, Revollo $S$, Lyèvre $P$, Muñoz $M$, Vargas $F$, Dedet JP. Parasitological diagnosis of mucocutaneous leishmaniasis due to Leishmania b. brasiliensis in Bolivia. Revista da Sociedade Brasileira de Medicina Tropical 24:231-234, out-dez, 1991

fixed in Bouin's fluid or $10 \%$ buffered formalin. The sections were stained with haemalum-eosinsafranine or Giemsa 's stain.

The immunological investigation realized in each patient included: leishmanin skin testing and detection of circulating antibodies by indirect immunofluorescence.

\section{RESULTS}

The patients were divided into 2 groups, according to the type of lesion (cutaneous or mucosal) they harboured.

\section{Patients with cutaneous lesions}

This group included 30 patients harbouring only cutaneous lesions. Of them, 23 were males and 7 females. The age range was $25.7+3.2$ years.

Three originated from Peru, the others were Bolivian.

The lesions were ulcerative, with marked inflammatory fringe. The lesions were unique in $36.6 \%$ of the patients and multiples en $63.3 \%$. They were localized on lower limbs in $53.8 \%$ of the cases and $86.6 \%$ of them had a duration period inferior to one year.

The parasite was found in 15 patients $(50 \%)$ according to the following identification techniques:

- positivity of smear alone: 2 cases $(13.3 \%)$

- positivity of culture alone: 3 cases $(20.0 \%)$

- positivity of pathology alone: 2 cases $(13.3 \%)$

- positivity of both smear and culture: 2 cases (13.3\%)

- positivity of both smear and pathology: 5 cases $(33.3 \%)$

- positivity of smear, culture and pathology: 1 case (6.6\%)

Table 1 shows the comparisons of the three identification techniques.

The six isolates otained in culture were characterized by isoenzyme electrophoresis as $L . b$. braziliensis ${ }^{5}$.

According to the duration period of the lesions, the parasite was found in $40 \%$ of the lesions of less than 1 year of evolution and in $75 \%$ of the lesions of more than 1 year of evolution.

The leishmanin skin test was positive in $82.1 \%$ and the IFI result was included between $1 / 40$ and 1/80 in $86.6 \%$ of the cases.

\section{Patients with mucosal lesions}

The second group of patients included 116 patients affected with mucosal leishmaniasis. One hundred nine were males and seven females. The age range was 3.7 to 38.5 years. Fifteen of them originated from Peru, the others were Bolivians. The evolution time of mucous involvement was less than 1 year in $12 \%$, between 1 and 5 years in $58.6 \%$, between 5 and 10 years in $21.5 \%$, between 10 and 20 years in $6 \%$ and more than 20 years in $1.7 \%$ of the cases. The extension of the mucosal involvement was limited (nose + palate mucosa) in $38.7 \%$, important (nose + palate mucosa + pharynx or larynx lesion) in $28.4 \%$ and very important (all the mucous of the otorhinolaryngeal (ORL) sphere) in $32.7 \%$ of the cases.

The parasite was found in 60 patients $(51.7 \%)$ according to the following identification techniques:

- positivity of smear alone: 10 cases $(8.6 \%)$

- positivity of culture alone: 15 cases $(12.9 \%)$

- positivity of pathology alone: 18 cases $(15.5 \%)$

- positivity of both smear and culture: 2 cases (1.7\%)

- positivity of both smear and pathology: 10 cases (8.6\%)

- positivity of smear, culture and pathology: 5 cases $(4.3 \%)$

The Table 1 shows the comparison of the three examination techniques in the two groups of patients.

The 15 isolates obtained from the 22 positive cultures were characterized as $L$. b. braziliensis by isoenzyme electrophoresis ${ }^{6}$.

Regarding the evolution time of the lesions, the parasite was found in $48.7 \%$ of the lesions of less than 5 years of evolution and in $58.8 \%$ of the lesions of more than 5 years of evolution.

The leishmanin skin test was positive in $75 \%$ and the IFI results included between $1 / 80$ and $1 / 160$ in $70.6 \%$ of the cases. 
Dimier-David L, David $C$, Ravisse $P$, Bustillos $R$, Revollo $S$, Lyèvre $P$, Muñoz $M$, Vargas F, Dedet JP. Parasitological diagnosis of mucocutaneous leishmaniasis due to Leishmania b. brasiliensis in Bolivia. Revista da Sociedade Brasileira de Medicina Tropical 24:231-234, out-dez, 1991

Tabela 1 - Comparison of the three identification techniques in the two groups of patients.

\begin{tabular}{|c|c|c|c|c|}
\hline & \multicolumn{2}{|c|}{ Cutaneous lesions } & \multicolumn{2}{|c|}{ Mucous lesions } \\
\hline & $\mathrm{N}^{0}$ & $\%$ & $\mathrm{~N}^{\circ}$ & $\%$ \\
\hline Patient number & 30 & & 116 & \\
\hline Positive smears & 10 & $(33.0)$ & $27 / 112$ & $(17.7)$ \\
\hline Positive culture & 6 & $(20.0)$ & $22 / 94$ & $(23.4)$ \\
\hline Positive pathology & 8 & $(26.6)$ & $33 / 116$ & $(28.4)$ \\
\hline $\begin{array}{l}\text { Number of patients with } \\
\text { positivie parasitology }\end{array}$ & 15 & $(50.0)$ & 60 & $(51.7)$ \\
\hline
\end{tabular}

\section{DISCUSSION}

The results of our study showed that using or techniques the percentage parasite positive patients in cutaneous and mucosal lesions of $L$. b. braziliensis leishmaniasis in Bolivia are similar: $50 \%$ in cutaneous lesions versus $51.7 \%$ in mucous lesions.

Compared to literature data these percentages appear weak in the case of cutaneous lesions: Cuba et al ${ }^{1}$ detected parasites in $71.2 \%$ of cutaneous lesions of the same mucocutaneous leishmaniais in Três Baços (Bahia, Brasil). Also in Bolivia, Desjeux et $\mathrm{al}^{2}$ obtained $48.6 \%$ positive results in parasite detection by culture and hamster inoculation in a sample of 72 cutaneous lesions biopsied from mucocutaneous leishmaniasis. In a 216 patients sample observed in French Guyana, smear and culture detection of the parasite were positive en $61.6 \%$ of the cutaneous lesions due to $L . b$. guyanensis (Dedet, unpublished data).

In respect to the mucous lesion, the positive percentage is equivalent to that of Cuba et al ${ }^{1}$ who observed $48 \%$ of positivity in mucosal lesions, but differs largely from the $100 \%$ positivity obtained in a limited sample of patients in Colombia by Saravia et $\mathrm{al}^{7}$.
According to our results, the most efficient parasite detecting techniques appeared to be the smears in cutaneous lesions (33.3\% of positivity) and the pathology in case of mucous lesions $(28.4 \%)$. For logistic reasons, hamster inoculation was not done although this is an efficient method of diagnosis. Our observation stresses the value of routine pathological method in the diagnosis of mucocutaneous leishmaniasis. This technique not only can give direct evidence of the parasite, as reported here, but can also allow the elimination of other pathologies as will be discussed in detail elsewhere ${ }^{3}$.

In our experience, the parasite was found more frequently in the cases of important and very important mucous extension $(57.7 \%$ positivity) than in the cases of limited involvement $(42.2 \%$ positivity). Marsden ${ }^{3}$ observed in the same way that it was "easier to detect parasites in multiple mucosal lesions than in single ones".

Another paradoxical data evidenced by our observation is that in both cutaneous and mucous lesions the parasites were found most frequently in old lesions (more than one year evolution for cutaneous lesions and more than 5 years evolution for mucous lesions) than in recent lesions, to the 
Dimier-David L, David $C$, Ravisse $P$, Bustillos $R$, Revollo $S$, Lyèvre $P$, Muñoz $M$, Vargas F, Dedet JP. Parasitological diagnosis of mucocutaneous leishmaniasis due to Leishmania b. brasiliensis in Bolivia. Revista da Sociedade Brasileira de Medicina Tropical 24:231-234, out-dez, 1991

contrary of other authors' observations $^{1410}$.

These observation illustrate the importance of further comparative studies, in order to show the variations due to local situations, both in lesion expression and in laboratory conditions.

\section{RESUMO}

Diagnóstico parasitológico, usando estregaço, cultura e exame anatomopatológico de biópsia, foi estudado em 146 pacientes infectados com leishmaniose mucocutânea, na Bolivia e Peru. A mais eficiente técnica de detectar parasitas parece ser o exame de esfregaço para lesões cutâneas (33\% de positividade) e anatomopatológico para lesões de mucosas (28\% de positividade). Em ambas lesões, cutânea e mucosa, parasitas foram mais frequentemente encontrados em velhas lesões.

Palavras-chaves: Leishmaniose mucocutânea. Leishmania b. braziliensis. Diagnóstico. Parasita. Bolivia. Peru.

\section{ACKNOWLEDGEMENTS}

We thank Pr. Fernando Cardenas and Pr. Luis Valda of the department of Dermatology, Hospital de Clínicas of $\mathrm{La} \mathrm{Paz}$, were the patients were hospitalised. The Instituto Boliviano de Biologia de Altura receives a support from the Ministère des Affaires Etrangères (Paris, France), the Ministerio de Previsión Social y Salud Pública and the Universidad Mayor de San Andrés (La Paz, Bolivia).

\section{REFERENCES}

1. Cuba CC, Llanos-Cuentas EA, Barreto AC, Magalhas AV, Lago EL, Reed SG, Marsden PD. Human mucocutaneous leishmaniasis in Três Baços, Bahia - Brazil. An area of Leishmania braziliensis braziliensis transmission. I. Laboratory diagnosis. Revista da Sociedade Brasileira de Medicina Tropical 17:161-167, 1984.

2. Desjeux P, Mollinedo S, Le Pont F, Paredes A, Ugarte G. Cutaneous leishmaniasis in Bolivia. A study of 185 human cases from Alto Beni ( $\mathrm{La} \mathrm{Paz}$ department). Isolation and isoenzyme characterization of 26 strains of Leishmania braziliensis braziliensis. Transactions of the Royal Society of Tropical Medicine and Hygiene 81:742746, 1987.

3. Dimier-David L, Ravisse P, Bustillos R, David C, Lyevre P, Mallea F, Valda L, Dedet JP. Histopathologie de la leishmaniose cutaneomuqueuse à Leishmania braziliensis braziliensis. Bulletin de la Societé de Pathologie Exotique (submitted).

4. Furtado TA. Diagnóstico laboratorial de leishmaniose tegumentar americana. Anais Brasileiros de Dermatologia 47:211-228, 1972.

5. Marsden PD. Mucosal leishmaniasis ("espundia" Escomel, 1911). Transactions of the Royal Society of Tropical Medicine and Hygiene 80:859-876,
1986.

6. Revollo S, Dimier-David L, David C, Lyevre P, Camacho C, Dedet JP. Isoenzymatic characterization of Leishmania braziliensis braziliensis isolates obtained from Bolivian and Peruvian patients. Transactions of the Royal Society of Tropical Medicine and Hygiene 86:388-391, 1992.

7. Saravia NG, Holguin AF, McMahon-Pratt D, D'Alessandro A. Mucocutaneous leishmaniasis in Colombia: Leishmania braziliensis subspecies diversity. The American Joumal of Tropical Medicine and Hygiene 34:714-720, 1985.

8. Shaw JJ, Lainson R. Ecology and Epidemiology: New World. In: The leishmaniasis in Biology and Medicine. Peters W, Killick-Kendrick $\mathbf{R}$ (ed). Academic Press, London 1 p.291-363, 1987.

9. Torres Espejo M, Le Pont F, Mouchet J, Desjeux P, Richard A. Epidemiologie de la leishmaniose tégumentaire en Bolivie. 1. Description des zones d'étude et fréquence de la maladie. Annales de la Société Belge de Médecine Tropicale 69:297-306, 1989.

10. Urgel R, De Muynck A, Recacoechea M, Azogue E. El diagnóstico de la leishmaniasis cutanea con particular referencia a los hallazgos parasitológicos. Boletín Informativo del Centro Nacional de Enfermedades Tropicales 6:31-37, 1980. 